\title{
Change in Trigeminal Somatosensory Evoked Potential (SEP) at Different Recording Sites in Cats
}

\author{
by \\ Koichi IWATA, Aiko IKUKAWA, Shigeru KITA, Osamu FUJII, \\ Kuniharu KONDOH and Rhyuji SUMINO
}

(Received 28 June 1985)

\section{Summary}

Trigeminal somatosensory evoked potentials (SEPs) were recorded from the scalp (A), the skull (B), the dura (C) and from the cortical surface (D) in compliance with the International 10-20 system in cats anesthetized with ketamine and immobilized with pancronium bromide. SEP amplitude decreased most when the recording sites moved from $\mathrm{C}$ to $\mathrm{B}$ and had the largest spread on $\mathrm{A}$. The intracortical distribution of evoked potentials was also examined at the area where the largest SEP value was obtained. With stimulation of the whisker pad, SEP's early positive wave $(\mathrm{P})$ changed reversely to a deep negative wave $(\mathrm{Nd})$ at the deep layers of the cortex, showing the largest amplitude at a depth of about $1.0 \mathrm{~mm}$ from the cortical surface. The amplitude then started to diminish as the electrode was inserted into the deeper layers. Conversely, a negative wave $(\mathrm{N})$ following $\mathrm{P}$, showed the largest amplitude just on the surface of the cortex.

\section{Introduction}

Change in somatosensory evoked potentials recorded from the scalp is believed to occur when an electric current generated in the brain reaches the scalp through the medium of volume conductance. There has been a variety of research on the change of electric potentials recorded from the human scalp ${ }^{[1]}$ and exposed brain ${ }^{[2,3]}$, PENFIELd et al. ${ }^{[5,6]}$ recorded the somatosensory evoked potentials directly from the human cortex to map the somatosensory area of man. The results of each research have largely been applied clinically, playing a vital role in detecting damage that has appeared in the human brain ${ }^{[4]}$. All of this research, however, had technical limitation in that the subjects were humans. Thus, SEP recordings have been limited to the surface of the cortex and the mechanism which generates SEPs inside the cortex has been still beyond reach.

In the present experiment, SEPs elicited by stimulation of the facial skin were recorded from the scalp, the skull, the dura, the cortical surface, and within the cortex in cats. The location of SEP generation within the cortex and the mechanism of SEP alteration from the place of origin to the scalp were also studied.

岩田幸一, 生川あい子, 北 滋, 藤井 宰, 近藤国晴, 角野隆二: Department of Physiology, Nihon University School of Dentistry. 


\section{Materials and Methods}

Nine adult cats weighing between 2.5 and $3.5 \mathrm{~kg}$ were used in this experiment. After they were anesthetized with $50 \mathrm{mg} / \mathrm{kg}$ of ketamine (SANKYO), a catheter was implanted into the radial vein and the trachea cannulated.

During the experiment, the blood pressure was monitored through a femoral arterial catheter. The rectal temperature was also monitored simultaneously, while maintaining the body temperature at 36 to $39^{\circ} \mathrm{C}$ with a heating pad. Subsequently, $10 \mathrm{mg} / \mathrm{kg}$ of ketamine was administered at alternate hours.

After mounting a cat on the stereotaxic apparatus (NARISHIGE), pancronium bromide (miobrock, ORGANON) was used to immobilize the animal and then whisker pad was stimulated (500 $\mu \mathrm{A}, 0.5 \mathrm{msec}$, single pulse) quantitatively using a constant current stimulator (NIHONKOUDEN, SEN-7103) and an isolator (NIHON KOUDEN, SS201J, SS201KB). Evoked potentials thus induced were recorded by fixing needle electrodes in the scalp, screws of about $0.5 \mathrm{~mm}$ diameter in the cranial bone and on the dura, and silverball electrodes of $0.5 \mathrm{~mm}$ diameter on the cortical surface, in compliance with the International 10-20 system. These three kinds of recording electrodes had approximately null impedances. Intracortically evoked potentials were recorded monopolarly with a glass coated tungsten microelectrode (impedance: about $0.5 \mathrm{M} \mathrm{ohm}$ ) equipped with a micromanipulator (NARISHIGE, MO951).

In recording the intracortical potentials, care was taken to insert a microelectrode vertically against the surface of the cortex. Also, the recording depth was determined by reading a micromanipulator $(\mu \mathrm{m})$.

After amplification with a differential amplifier (NIHONKOUDEN, S1516), (time constant $0.3 \mathrm{msec}$, Hi-cut $1 \mathrm{KHz}$ ), recording was held in a data recorder (SONY, A-49).

Before analysis, a hundred sweeps were averaged with a SIGNAL PROCESSOR 7T-17 (NIHONDENKI SANEI). After recording evoked potentials, recording points were marked by passing a direct current of $10 \mu \mathrm{A}, 10 \mathrm{sec}$. After the experiment, the brains were extracted and fixed in $10 \%$ neutral formalin and then serial sections measuring $50 \mu \mathrm{m}$ were prepared.

\section{Results}

Evoked potentials elicited by stimulation of the contralateral facial skin were found to consist of a positive wave (P) and a following negative wave $(\mathrm{N})$, regardless of whether recording sites were on the scalp, in the skull, on the dura or on the cortical surface. The area where $\mathrm{P}$ and $\mathrm{N}$ showed large values, corresponded with the opposite site of the frontal cortex in terms of stimulation. This cortical area coincided with the cat's somatosensory area as reported by WoOLSEY et al. ${ }^{[7,8]}$.

\section{SEP Alteration from Scalp to Cortex}

Fig. 1 shows SEPs recorded from the scalp (A), the skull (B), the dura (C) and from the cortical surface (D), with the electrodes situated in accordance with the International 10-20 system. A large value of evoked potential was obtained at 


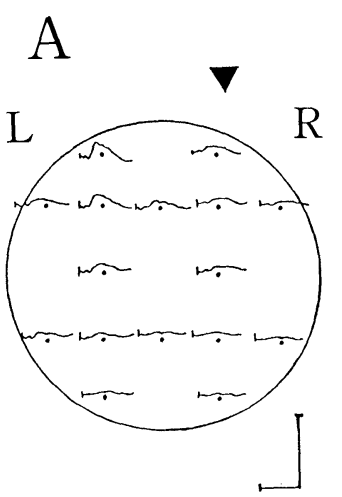

$\mathrm{C}$
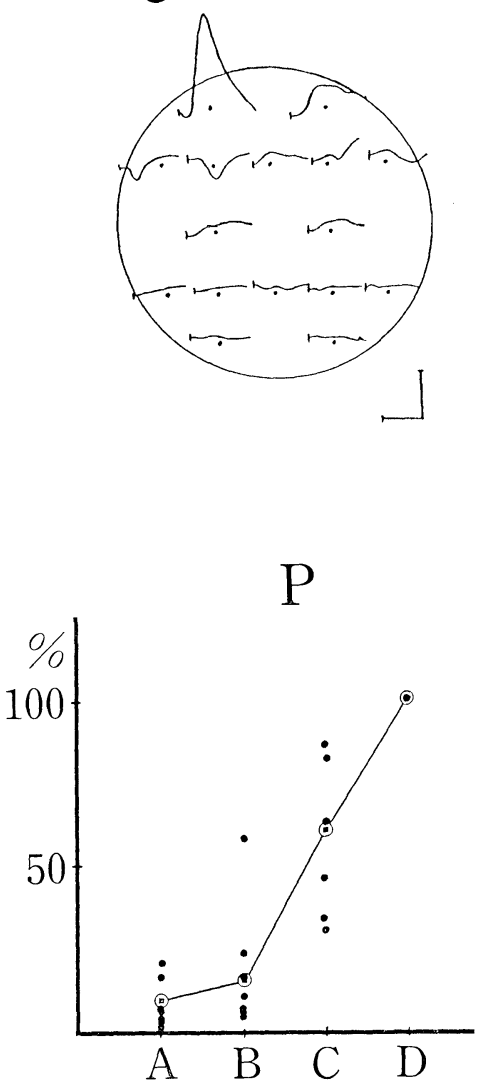

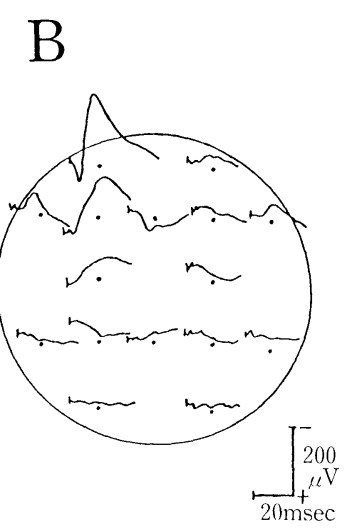

D
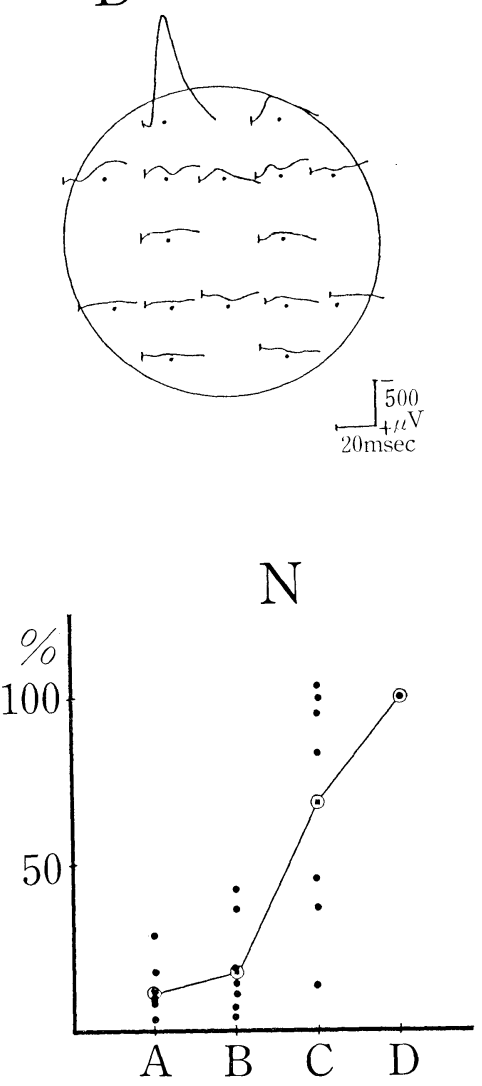

Fig. 1 Distribution of somatosensory evoked potentials (SEPs) recorded at 16 different points on the scalp (A), in the skull (B), from the dura (C), and the cortical surface (D) respectively, by stimulation of the right whisker pad with a single pulse of $500 \mu \mathrm{A}, 0.5 \mathrm{msec}$. The upper part of each circle shows the cat's frontal region and the left side of the circle shows the cat's left region. Recording electrodes are arranged in accordance with the International 10-20 system and each SEP has 

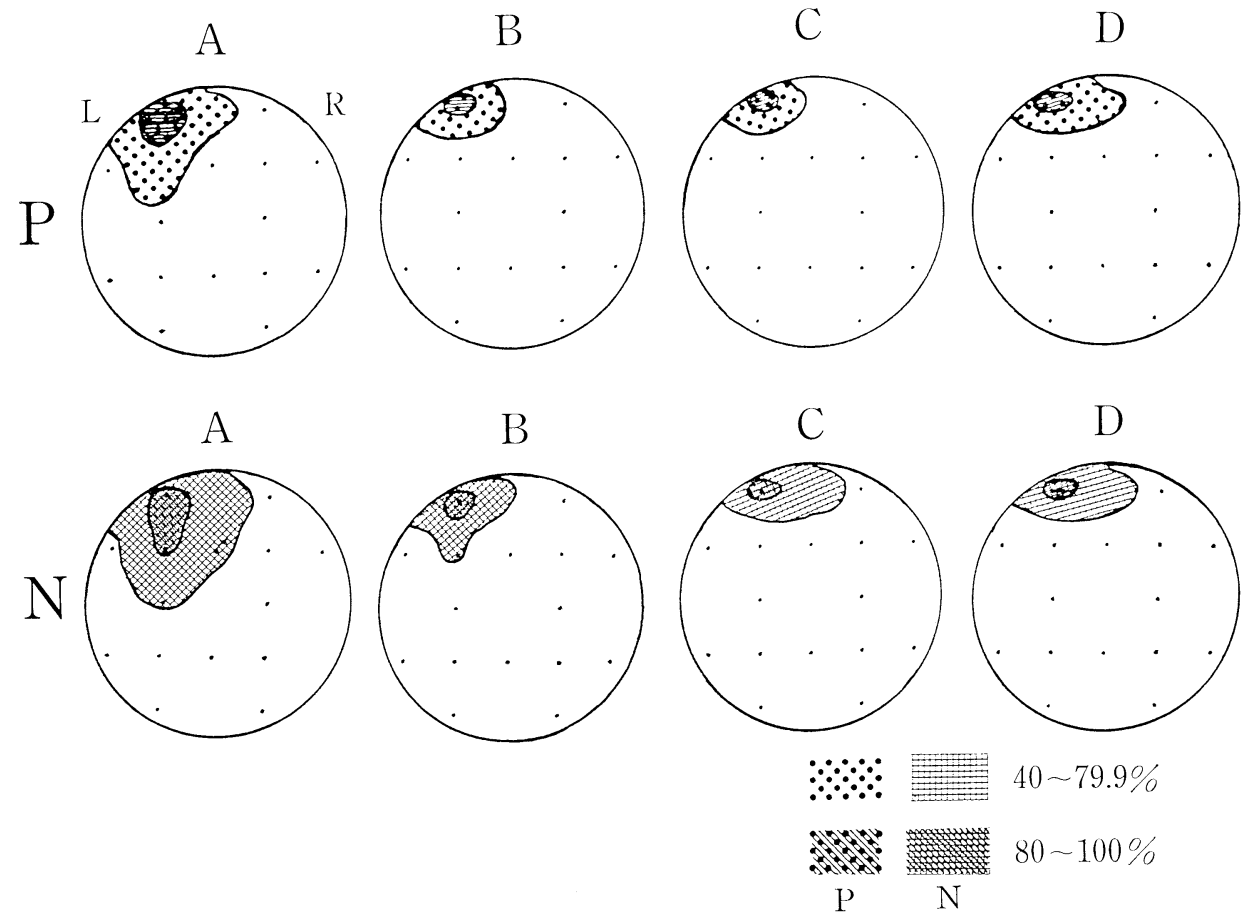

D

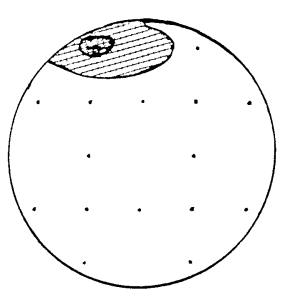

40 $79.9 \%$

$80 \sim 100 \%$

Fig. 2 SEPs at each recording site of $\mathrm{A}, \mathrm{B}, \mathrm{C}$, and $\mathrm{D}$ are divided into $\mathrm{P}$ and $\mathrm{N}$ according to the size and the extent of each is shown in relative values. A percentage of each pattern is shown in the lower right corner. Note that both $\mathrm{P}$ and $\mathrm{N}$ show the largest spread at $\mathrm{A}$.

the limited area of the left frontal cortex, even when the recording position moved from $A$ to $D$. In all of these cases, the response waves consisted of $P$ and $N$. The smallest value for amplitude of evoked potential was obtained at $\mathrm{A}$, while the degree of amplitude increased in both $\mathrm{P}$ and $\mathrm{N}$ as the recording position moved from $\mathrm{B}$ to $\mathrm{D}$. In the lower part of Fig. 1 is shown a systematic change of amplitude from $\mathrm{A}$ to $\mathrm{D}$, where it is $100 \%$. Both $\mathrm{P}$ and $\mathrm{N}$ show a similar trend of change with a small amplitude at $\mathrm{A}$ and $\mathrm{B}$ and a sudden increase in value at $\mathrm{C}$ and $\mathrm{D}$. The greatest value of amplitude was obtained at D. As shown in Fig. 1, large evoked potentials were recorded in the frontal cortex, probably because this area corresponded to the somatosensory cortex of the cat. Fig. 2 shows the spread of $\mathrm{P}$ and $\mathrm{N}$ components of SEPs, with the largest amplitude in relative values being $100 \%$. Both $\mathrm{P}$ and $\mathrm{N}$ were spread most widely on D. Fig. 3 shows latency and time to

been put through a 100 time-averaging process. Upper direction on each record shows negativity in this and following figures. Calibration for each record is shown at the bottom right-hand corner. In the lower part of this figure, SEPs are divided into positive wave $(\mathrm{P})$ and negative wave $(\mathrm{N})$ and the relative value of amplitude at each recording site against $\mathrm{D}$ whose amplitudes of $\mathrm{P}$ and $\mathrm{N}$ are rated $100 \%$. The ordinate shows the relative amplitude and the abscissa shows recording points. Note that both $\mathrm{P}$ and $\mathrm{N}$ change most as they move from $\mathrm{B}$ to $\mathrm{C}$. 


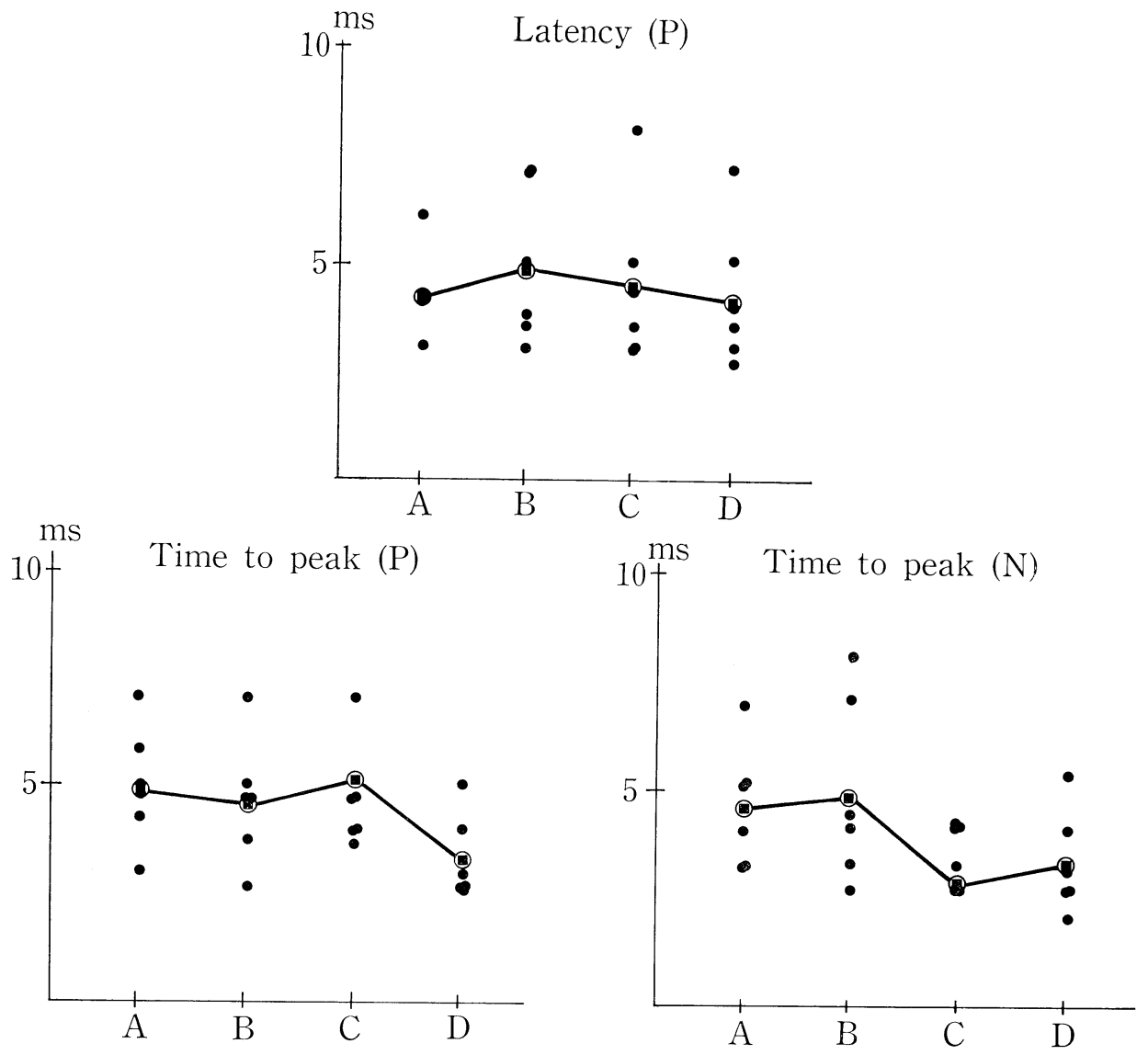

Fig. 3 Latency of $\mathrm{P}$ and time to peak for $\mathrm{P}$ and $\mathrm{N}$ at each recording site of $\mathrm{A}, \mathrm{B}, \mathrm{C}$ and $\mathrm{D}$. In each graph, the ordinate shows the time and the abscissa shows the recording sites.

peak of SEPs followingsti mulation at each of the recording sites. According to the results of this experiment, there was no noticeable difference in latency in each recording site, but slightly smaller values for time to peak for both $\mathrm{P}$ and $\mathrm{N}$ were obtained at D than at A, B and C.

\section{Intracortical Distribution of Evoked Potentials}

The left side of Fig. 4 shows the distribution of $\mathrm{P}$ and $\mathrm{N}$ of evoked potentials recorded at the somatosensory area on the cortical surface opposite the whisker pad which was stimulated at a single pulse at $500 \mu \mathrm{A}, 0.5 \mathrm{msec}$. Size of the circles represents the relative value of the amplitude with the largest being $100 \%$. Large $\mathrm{P}$ and $\mathrm{N}$ were obtained within the same limit of the coronal gyrus near the point where the extended line of the cruciate sulcus intersected the coronal sulcus. The intracortical distribution of SEPs at the position where the largest values of $\mathrm{P}$ and $\mathrm{N}$ were obtained on the cortical surface is shown at the center of Fig. 4. P changed 

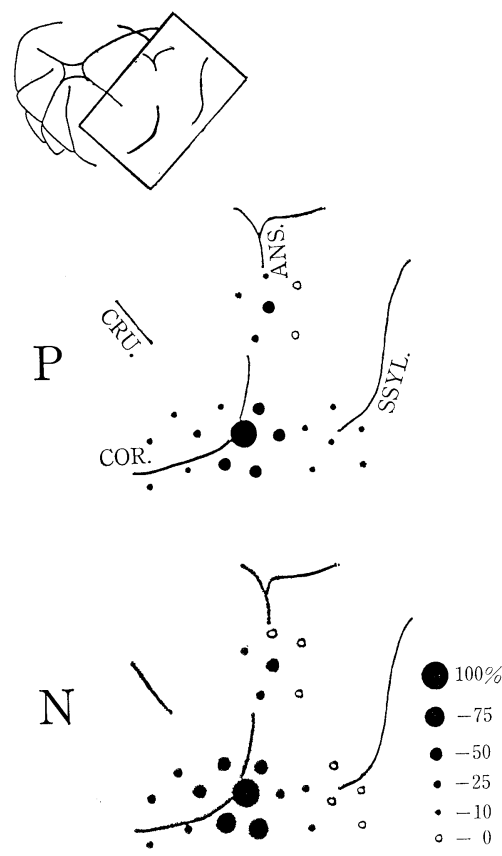
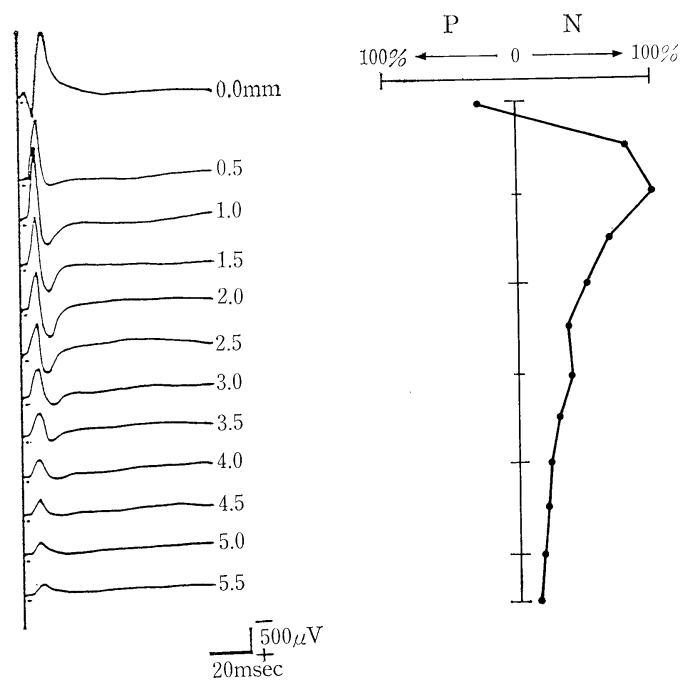

Fig. 4 Distribution of SEPs recorded at twenty points on the cortical surface when the whisker pad is stimulated by a single pulse of $500 \mu \mathrm{A}, 0.5 \mathrm{msec}$. SEPs are divided into $\mathrm{P}$ and $\mathrm{N}$ and the size of a solid circle indicates the relative amplitude of each P. Large values of evoked potentials were obtained, for both $\mathrm{P}$ and $\mathrm{N}$, at the coronal gyrus near the point of intersection between the extension of the cruciate sulcus and the coronal sulcus. A fronto-lateral view of a cat's cortex is shown in the upper left corner. In its center is shown the intracortical distribution of SEPs at various depths, indicated by the right of each record, in the areas where the largest values of $\mathrm{P}$ and $\mathrm{N}$ were obtained. On the right side of Fig. 4 is shown the relative percentage of the amplitude of evoked potentials recorded at the same depth of the intracortical distribution, where the greatest deep negative wave $(\mathrm{Nd})$ was $100 \%$. Note that the greatest value of $\mathrm{Nd}$ can be recorded at a depth of $1.0 \mathrm{~mm}$ from the surface of the cortex.

reversely to a deep negative wave $(\mathrm{Nd})$ at a depth of $0.5 \mathrm{~mm}$ from the surface of the cortex. This $\mathrm{Nd}$ showed the greatest amplitude at a depth of $1.0 \mathrm{~mm}$ and the value of amplitude diminished at the deeper layers. Shown on the right side of Fig. 4 , is an intracortical transition of $\mathbf{P}$, obtained from the cortical surface, to $\mathrm{Nd}$ in the deeper layers, with the largest $\mathrm{Nd}$ being $100 \%$.

All results described above are summarized in Fig. 5. The amplitude of the evoked potential, $\mathrm{P}$ and $\mathrm{N}$, recorded at $\mathrm{D}$, diminished as the recording positions moved from $\mathrm{C}$, to $\mathrm{B}$ and to A. A hypothetical scheme of the current flow which produced $\mathrm{P}$ and $\mathrm{N}$ on the cortical surface is shown on the left side of Fig. 5. Where the thalamus makes a synapse linkage with the cortical cells, a sink of electric current occurs, thereby forming a source at the cortical surface. On the other hand, $\mathrm{N}$ is presumably generated by the synapse linkage at an apical dendrite near the cortical surface, which serves as a sink. $\mathrm{P}$ and $\mathrm{N}$ thus appearing on the cortical surface are 


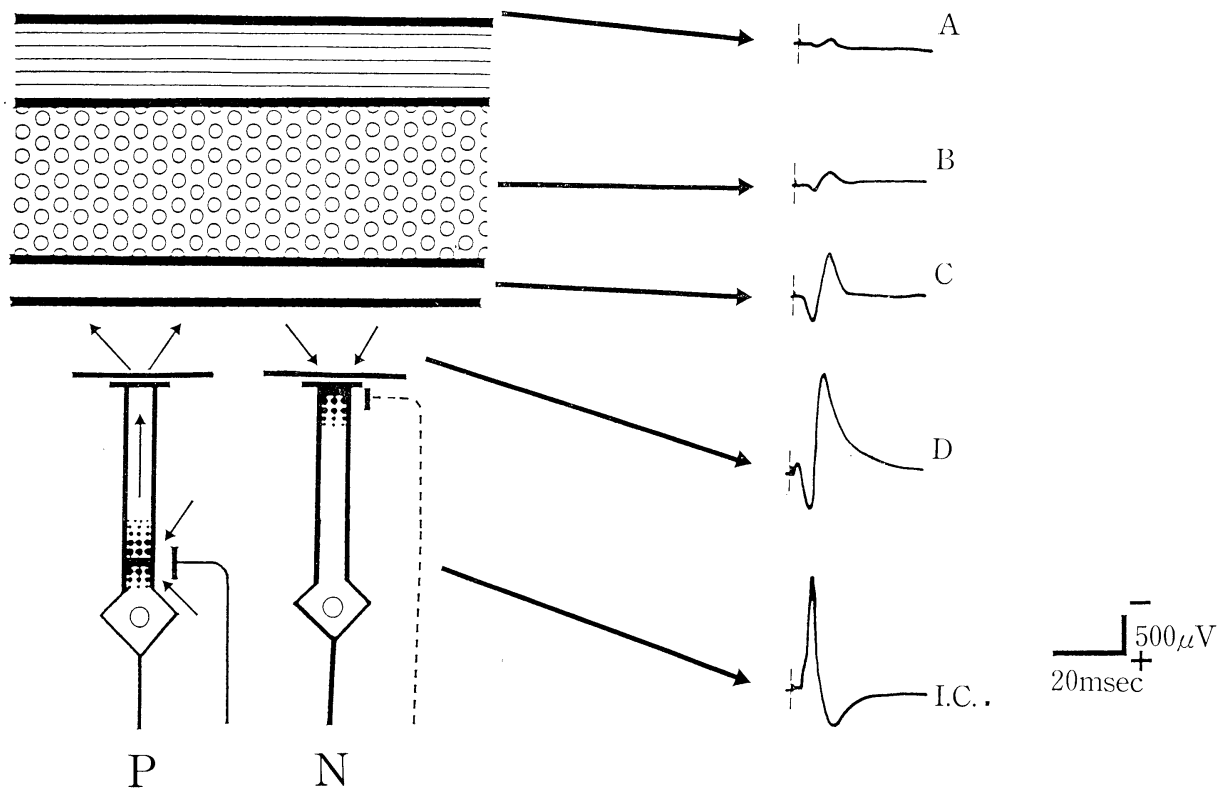

Fig. 5 A hypothetical scheme of the origin of $\mathrm{P}$ and $\mathrm{N}$ and evoked potentials at each recording site of A, B, C and D. The arrow ( $\uparrow$ ) in the scheme shows the direction of flow of electric current. In the lower-right corner is shown the calibration of each record. I.C.: intracortical.

believed to spread electrotonically over the cortex through the dura, the skull and finally to the scalp.

\section{Discussion and Conclusions}

Somatosensory evoked potential (SEP), recorded from the scalp by stimulation of the human skin in the trigeminal region, shows a complicated wave form, often making it difficult to obtain a stable response ${ }^{[9,10,11]}$. This is also true of stimulation of the medial nerve, as JONES reported ${ }^{[21]}$. However, the early response with a short latency can be recorded in a comparatively more stable condition than the following long latency responses ${ }^{[22]}$, but no consensus is yet available concerning the sort of change in intracortical electric potential which causes the early response of SEP recorded from the scalp. AlLison et al. ${ }^{[12]}$ and GofF et al. ${ }^{[13]}$ claim that, as far as primates are concerned, both the positive wave (P) and negative wave (N) of SEP with the shortest latency derived from the synaptic potential were generated by the thalamocortical connection. LI et al. ${ }^{[14,15,16]}$ surmised that in cats, of SEPs recorded at the somatosensory cortex by skin stimulation, the early positive wave would be generated by an input coming through a specific thalamocortical pathway, projecting to the cortex and thus making a synapse linkage with the cortical cells at that part. In this experiment, SEPs of cats consisted of $\mathrm{P}$ and $\mathrm{N}$ with the shortest latency. As in humans, cat $\mathrm{P}$ and $\mathrm{N}$ are also thought to be generated by the input reaching the cortex by way of the same route, considering the conduc- 
tion time of the peripheral and central nervous systems in both cat and human. Normally, the electric current generated on the cortex is believed to change during transmission to the scalp, due to volume conductances, namely impedance and capacitance, that exist between the cortex and the scalp. In other words, the living body can be regarded as a form of RC circuit. Based on this idea, the capacitance in the living body affects the lapse of time in which the electric potential alters and changes the shape of the response wave. If the degree of capacitance increases, it takes a longer time to reach the response peak. The impedance also affects the amplitude of the response. A large impedance diminishes the amplitude. According to our results, both $\mathrm{P}$ and $\mathrm{N}$ of the SEP recorded on the scalp showed no change in latency with shift of recording electrodes from the scalp (A) onto the dura (B), and the cortex (C), while time to peak showed slightly smaller values at D than at $\mathrm{A}, \mathrm{B}$ and $\mathrm{C}$. Taking the afore-mentioned factors into consideration, this change in time to peak resulted from the influence of the capacity components in the living body.

Both $\mathrm{P}$ and $\mathrm{N}$ showed the greatest amplitude at $\mathrm{D}$, with the value being far larger than at any other recording position. The decline in amplitude may have resulted from the impedance existing within body structures between the recording electrode and the ground, if impedances of all three kinds of electrodes were approximately null, as mentioned in METHODS. According to the results of this experiment, $\mathrm{P}$ amplitude in SEP decreases with shift in the recording electrodes. For instance, the $\mathrm{P}$ amplitude which was rated $100 \%$ on the cortex decreased to about $61 \pm 2 \%$ on the dura and further to $12 \pm 20 \%$ in the skull. On the other hand, there was no conspicuous difference between the values recorded from the scalp and in the skull. The same trend was found with N. These facts lead us to surmise that, in recording SEP, the skull has the largest impedance which affects the amplitude most.

Furthermore, the comparison of SEP recorded at the wide area of the scalp with that recorded at the cortical surface, shows that both $\mathrm{P}$ and $\mathrm{N}$ on the scalp appear more extensively than those on the cortical surface. These results agree with those of ArEzzo et al. ${ }^{[17]}$ who recorded SEP of primates from the skull and the dura by medial nerve stimulation. This is understandable on the assumption that there is a sequence of RC circuit spreading horizontally on A, B, C and D respectively, and that the scalp has the smallest impedance among $\mathrm{A}, \mathrm{B}, \mathrm{C}$ and $\mathrm{D}$.

Furthermore, considering that shifting the electrode from the scalp onto the cortex does not cause any change in the area where the largest evoked potential is recorded, there seems to be an area providing a source or sink of electric current on the cortex, directly under the scalp where a large amplitude of SEP is recorded.

As mentioned previously, SEP recorded from the cortical surface is known to be caused by the electric current generated in the deeper layers of the cortex ${ }^{[14}$, ${ }^{15,16]}$. According to our results, $P$ recorded from the cortical surface changes reversely to a negative wave $(\mathrm{Nd})$ at a depth of about $0.5 \mathrm{~mm}$ from the surface of the cortex and this $\mathrm{Nd}$ showed the greatest amplitude at a depth of $1.0 \mathrm{~mm}$, gradually reducing thereafter. Based on research until the present, it is presumed that when $\mathbf{P}$ shows the largest amplitude after changing reversely to $\mathrm{Nd}$, the origin of $\mathrm{Nd}$ is the ex- 
citatory postsynaptic potential (EPSP) generated in the cortical cells or apical dendrite by input through the thalamus ${ }^{[18,19]}$. IKUKAWA et al. ${ }^{[20]}$ studied the intracortical distribution of evoked potentials by stimulation of the facial skin and the masseteric nerve of the cat and compared this distribution with the area where single neuronal activity by the same stimulation is recorded. They reported the existence of a high density layer of these neurons where the $\mathrm{Nd}$ of evoked potential displays the largest amplitude at the coronal gyrus.

All these lead us to predict that on the layer where the largest $\mathrm{Nd}$ is recorded, the input from the thalamus undergoes synapse coupling with the cortical cells, forming a sink of electric current. Since a large amount of neuronal activity is recorded in the vicinity of this layer, a layer with a synapse coupling deep in the cortex is estimated to be quite near the cortical cell bodies.

Various reports are available concerning the origin of $\mathrm{N}$, but a consensus of opinion has not yet been obtained ${ }^{[14-16]}$. However, it is likely that a synapse coupling exists at the layer where the negative wave is recorded because such a layer forms a sink of electric current similar to that where $\mathrm{Nd}$ is recorded. In other words, $\mathrm{N}$ is believed to derive from the source of electric current generated at the site of synapse coupling existing on dendrites near the cortical surface.

Based on the foregoing discussion, it is inferred that the origin of early $\mathbf{P}$ and $\mathrm{N}$ in SEPs recorded from human scalp, is an alteration of electric potential appearing at the deeper layers where a synapse coupling exists in the cortex. It is further assumed that electric current generated at the synapse forms a sink or source on the cortical cells, thus causing $\mathrm{P}$ and $\mathrm{N}$ to appear on the cortical surface. Thus, they reach the scalp through such volume conductances as the dura, the skull and the cranial skin. Based on a number of research reports, the electric current generated in this synapse is likely to be driven by sensory input through a specific thalamocortical projection system.

\section{Acknowledgments}

We are honored to report that part of this study was supported by the Ota Overseas Exchange Fund and the Sato Scholarship of Nihon University School of Dentistry.

\section{References}

[1] Cracco, R.Q. and Cracco, J.B.: Somatosensory evoked potential in man: far field potentials, Electroencephal. Clin. Neurophysiol., 41, 460-466, 1976

[2] Kelly, D., Goldring, S. and O'leary, J.: Averaged evoked somatosensory responses from exposed cortex of man, Arch. Neurol., 13, 1-9, 1965

[3] Larson, S.J. and SANCES, A.: Averaged evoked potentials in stereotaxic surgery, IEEE Transactions on Bio-Medical Engineering, 12, 227-232, 1967

[4] Domino, E.F., Matsuoka, S., Walts, J. and Cooper, I.S.: Effects of cyrogenic thalamic lesions on the somesthetic evoked response in man, Electroencephal. Clin. Neurophysiol., 19, 127138,1965

[5] Penfield, E. and Rasmussen, T.: The cerebral cortex of man, Macmillan, New York, 1950

[6] Penfield, W. and JAsper, H.: Epilepsy and the functional anatomy of the human brain, Little Brown, Boston, 1954

[7] Woolsey, C.N. and FAIRMAn, D.: Contralateral ipsilateral and bilateral representation of cutaneous receptors in somatic areas I and II of the cerebral cortex of pig, sheep and other mammals, Surgery, 19, 684-702, 1946 
[8] Woolsey, C.N.: Organization of somatic sensory and motor areas of the cerebral cortex, In: Biological and Biochemical Basis of Behavior, Eds. Hallow, H.F. and Woolsey, C.N., 6381, Univ. Wisconsin Press, Madison, 1958

[9] OKa, N., Sueyoshi, K. and Makino, H.: Somatosensory evoked potential elicited by mechanical stimulation of the trigeminal nerve, Clin. Electroencephal., 9, 539-594, 1981 (in Japanese)

[10] Oka, N., Saeki, N., Odaki, M. and Takase, M.: Somatosensory evoked potentials following transcutaneous electrical stimulation of the trigeminal nerve, Clin. Electroencephal., 9, 539-594, 1981 (in Japanese)

[11] OKa, N.: Somatosensory evoked potentials of trigeminal nerve by electrical stimulation, normal finding and clinical applications, Chiba Med. J., 58, 289-296, 1982 (in Japanese)

[12] Allison, T., Goff, W.R., Williamson, P.D. and VanGilder, J.C.: On the neural origin of early components of the human somatosensory evoked potential. In: K.E. Desmedt (ed.), Progress in Clinical Neurophysiology, Karger, Basel, 1978

[13] Goff, W.R., Allison, T. and Vaughan, Jr., H.G.: The functional neuroanatomy of eventrelated potentials, In: E. Gallaway and S.H. Koslow (Eds.), Event-Related Brain Potentials in Man, Academic Press, New York, 1978

[14] Li, C.L., Cullem, C. and JASPER, H.H.: Laminar microelectrode studies of specific somatosensory cortical potentials, $J$. Neurophysiol., 19, 111-130, 1956

[15] ECCLES, J.C.: Brain and conscious experience, Springer Verlag, New York, 1966

[16] Amassian, V.E. and Waller, H.J.: Neuronal mechanism of the primary somatosensory evoked potential: Sensory evoked response in man, Ed., Whispple, H.E., Ann. N.Y. Acad. Sci., 112, 5-32, 1964

[17] Arezzo, J., Legatt, A.D. and Vaughan, Jr., H.G.: Topography and intracranial sources of somatosensory evoked potentials in the monkey I. Early components, Electroencephal. Clin. Neurophysiol., 46, 155-172, 1979

[18] Sasaki, K., Staunton, H.P. and Dieckmann, G.: Characteristic features of augmenting and recruiting responses in the cerebral cortex, Exp. Neurol., 26, 369-392, 1970

[19] Sasaki, K. and Prelevic, S.: Excitatory and inhibitory influence of thalamic stimulation on pyramical tract neurons, Exp. Neurol., 36, 319-335, 1972

[20] Ikukawa, A., Iwata, K. and Sumino, R.: Intracortical distribution of somesthetic driven neurons and somatosensory evoked potentials in SI region of cat cerebral cortex, Jpn. J. EEG $E M G$, Suppl., 13, 29, 1985 (in Japanese)

[21] JONES, S.J.: Short latency potentials recorded from the neck and scalp following median nerve stimulation in man, Electroencephal. Clin. Neurophysiol., 43, 853-863, 1977

[22] Iragui-Madoz, V.J. and Wiedenholt, W.C.: Far-field somatosensory evoked potentials in the cat: Correlation with depth recording, Ann. Neurol., 1, 569-574, 1977 